\title{
Experimental validation of numerical static calculations for a monolithic rectangular tank with walls of trapezoidal cross-section
}

\author{
W. BUCZKOWSKI, A. SZYMCZAK-GRACZYK*, and Z. WALCZAK \\ Poznań University of Life Sciences, Institute of Construction and Geoengineering, 94 Piątkowska St., 60-649 Poznań, Poland
}

\begin{abstract}
The article presents the results of validation of static calculations carried out for a monolithic rectangular tank with walls of trapezoidal cross-section. Static calculations were made with the use of software based on the finite element method (FEM) and the finite difference method (FDM) in terms of energy (including spatial static work of the tank). Validation of the results was conducted on a concrete tank model using an innovative measurement tool, i.e. a coordinate measuring arm with a touch probe.
\end{abstract}

Key words: rectangular tank, walls of trapezoidal cross-section, finite difference method, coordinate measurement arm.

\section{Introduction}

Rectangular tanks have been used as engineering structures for many years inter alia at sewage treatment plants, water treatment plants or at recreational facilities. In most cases they are made with walls of constant thickness but the use of trapezoidal cross-section walls is amply justified in structures where the load distribution is triangularly shaped, e.g. when hydrostatic pressure acts on walls. Since the load increases with an increase in depth, the wall thickness should accordingly increase with depth, too. Undoubtedly, tank walls of variable thickness require less material. The design of such facilities and particularly their production, however, is more demanding than it is with walls of constant thickness. Major difficulties in designing tanks with variably thick walls might presumably be caused by the relatively small number of available publications on plates or tanks of this type. One of the most recent studies available is the work by [1], in which the authors comprehensively discuss problems associated with the design and construction of reinforced concrete tanks for liquids. Yet the paper does not address specific issues concerning the design of tanks with trapezoidal cross-section walls. Reflections on advantages of tank walls with linearly variable thickness contributed to constructing a monolithic rectangular tank with the following external dimensions: $143 \mathrm{~cm}$ in length, $83 \mathrm{~cm}$ in width and $80 \mathrm{~cm}$ in height at the laboratory of Institute of Civil Engineering and Geoengineering, Poznań University of Life Sciences. The thickness of walls was variable, ranging from $2 \mathrm{~cm}$ at the top to $6 \mathrm{~cm}$ at the bottom, while the bottom thickness was $6 \mathrm{~cm}$. The tank was made of self-compacting concrete $\mathrm{C} 16 / 20$, without reinforcement. The composition of the concrete mixture used to make the tank is shown in Table 1. Based on the compressive

\footnotetext{
*e-mail: anna.szymczak-graczyk@up.poznan.pl
}

strength test, the concrete class was determined as C16/20 and the value of concrete elasticity modulus was adapted from the EU standard [2] $\mathrm{E}=30 \mathrm{GPa}$.

Table 1.

Composition of the concrete mixture used to make the tank

\begin{tabular}{|c|c|c|}
\hline \multicolumn{2}{|c|}{ Composition of concrete } & $\begin{array}{c}\text { Quantity } \\
\text { of components } \\
\text { per 1 m }\end{array}$ \\
\hline cement & CEM I 42.5 R & $450 \mathrm{~kg}$ \\
\hline aggregate & sand 0-2 mm & $1621.64 \mathrm{~kg}$ \\
\hline additive & fly ash & 110.76 \\
\hline admixture & plasticizer: Schomburg & $4.5 \mathrm{~kg}$ \\
\hline water & & $192.09 \mathrm{~L}$ \\
\hline
\end{tabular}

The tank is shown in Fig. 1.

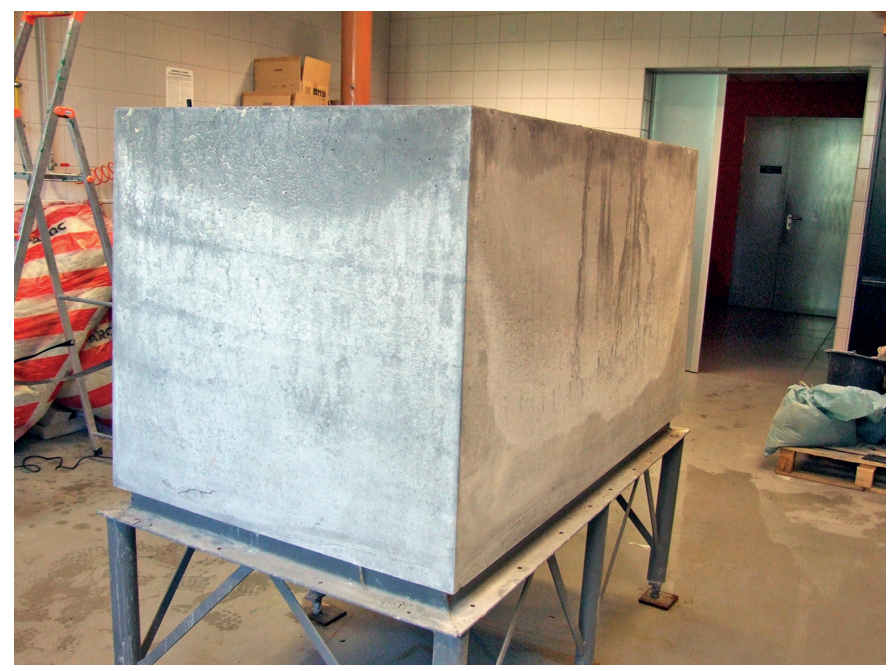

Fig. 1. Concrete tank before the experiment 
Traditional static calculations were carried out for the structure, which was subject to hydrostatic pressure on the entire depth of the tank. The finite difference method in terms of energy and computer-aided calculations by Autodesk Robot Structural Analysis Professional software, based on the finite element method, was used in these calculations. In order to simplify them, the authors assumed that $v=0$. The concrete deformation model for FEM was adopted as elastic. Rigidity in individual nodes of the FDM mesh applied was calculated analogously as in the case described for beams in [3].

Validation of the results was conducted on the modelled tank, which was subject to hydrostatic load resulting from its complete filling with water. Deformations at selected points of walls under the load applied were measured with the use of the FaroArm coordinate measuring device [4].

\section{Static calculations}

Static calculations were carried out for the tank taking into consideration its spatial static work. One of the methods that can be used for this type of computation is the finite difference method (FDM) in terms of energy. The subject matter has been considered by e.g. [5-10]. The functional that describes the energy of elastic flexibility of the plate being bent, excluding temperature load and the effect of a Winkler-type elastic foundation and assuming Poisson's ratio $v=0$, adopted from [5], takes the following form:

$$
V=\frac{D_{i}}{2} \iint_{A}\left(w_{x x}^{2}+2 w_{x y}^{2}+w_{y y}^{2}\right) d A-\iint_{A} p w d A
$$

where:

w - plate deformation,

$\mathrm{D}_{\mathrm{i}}$ - plate rigidity in particular nodes dependent on the wall thickness,

A - plate area,

p - load perpendicular to the central surface of the plate.

For FDM calculations the authors used a quadrilateral mesh with square-shaped cells. Taking into account the topological symmetry, a system of equations with 212 unknowns was received for half of the tank. It was followed by calculating the values of coefficients proportional to deformations for each point of the mesh applied. The only load taken into account in calculation was the hydrostatic load acting on walls and the bottom of the tank. By including previously designated material data $(E, v)$ and actual dimensions, the values of deformations at specified points of the tank were calculated.

In order to verify calculations carried out conventionally as well as for comparative purposes, calculations with Autodesk Robot Structural Analysis Professional software, based on the finite element method, were also made. [11] discusses the possibility of introducing BIM (Building Information Modelling) technology that will facilitate design works and coordination of investment processes by mentioning Autodesk Robot Structural Analysis Professional software as the basic tool for design engi- neers. Computer-aided calculations are included in publications by $[1,12]$ as well as [13]. Dimensions of the tank along with the mesh for FDM and FEM calculations were applied in accordance with the geometry of an experimental model, modelling the same layout of nodes for both meshes. The results obtained for selected points of the mesh, both for traditional (FDM) and computational calculations, are presented in the further part of the article and compared to experimental measurements (Table 2). The comparative analysis of results obtained when using the finite difference method and the finite element method has also been raised by [14].

\section{Experimental validation}

Experimental validation was carried out with the use of the FaroArm measuring device. A diagram of the measurement procedure applied is presented in Fig. 2.

Coordinate measuring arms are portable machines designed to optionally work in the immediate vicinity of a test element. The use of arms in engineering as well as the automotive and aerospace industry is presented by [15]. A coordinate measuring arm consists of three longitudinal elements interconnected with joints, onto which angle encoders are mounted. Angle encoders are characterized by a high degree of measuring and bearing accuracy when positioning individual elements of a coordinate measuring arm. Additionally, such an arm is provided with a counterweight that compensates for its weight and also allows for uninterrupted work. The mechanical structure of an arm is supplemented with a holder that attaches the arm to a stable stand or to the ground. It is equipped with a measuring probe to which a sensor is attached. Reference [16] presents methods of taking measurements with contact and non-contact measuring probes. The author defines scanning measurements carried out with probes with rigid tips as pseudo-scanning due to the fact that points are collected when the operator frequently presses the probe's trigger, whereas real scanning measurement is carried out in a non-contact way. However, [17], in their comparative study of data collection methods by means of contact and

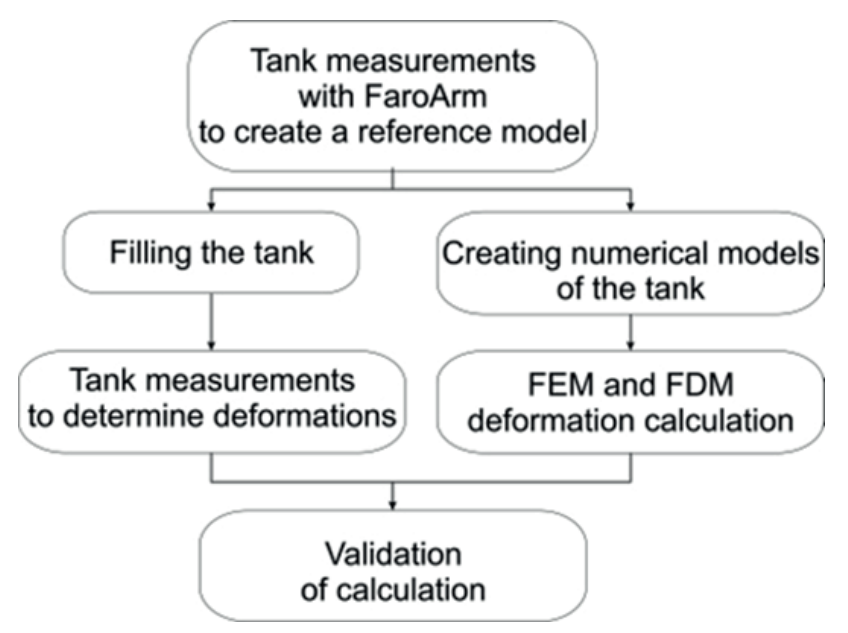

Fig. 2. Diagram of the measurement procedure applied 
non-contact measuring, present the thesis that higher measurement accuracy is achieved with the use of touch probes. The work refers to comparative measurements taken with the use of a measurement arm having a touch probe and a touch-trigger probe. When measuring with a rigid probe, the pressure depends on the operator while, in contrast, touch-trigger probe measuring implies that the tip contacts the surface automatically, for the movement is generated by means of a touch-trigger transducer. Tests have shown that measurements taken with the use of a rigid touch probe are more accurate. Measurement takes place when the arm is applied to a measured object and its measuring tip contacts a measured surface. After confirming a contact point between the sensor and the surface, the point coordinates are read from encoders placed at joints. The location of angles or the values by which measured objects have been rotated are converted to local Cartesian topology using dedicated software. The most advanced measuring devices are equipped with modules for direct data transfer to a computer with relevant measurement software. FaroArm's measurement range is $1.8 \mathrm{~m}-3.7 \mathrm{~m}$, whereas its repeatability varies from $0.024 \mathrm{~mm}$ to $0.064 \mathrm{~mm}$, depending on the length of the measurement arm. Volumetric accuracy of the device is $\pm 0.034 \mathrm{~mm}$ and single point repeatability reaches $0.024 \mathrm{~mm}$. The literature provides numerous publications that discuss measurements of building structures with the use of laser scanning, however there are no measurements taken with a measurement arm.

Measurements of displacements for selected points on walls of the concrete tank subject to hydrostatic load were carried out using the FaroArm measuring device with the length of $1.8 \mathrm{~m}$ having a rigid touch probe. It proceeded in two stages. The first stage consisted in measuring an empty tank for structural modelling in software, while the next stage involved measuring the displacements of walls of the tank fully filled with water. Figure 3 and Fig. 4 show the empty tank during measurements. Tank walls have a square measuring mesh $(10 \times 10 \mathrm{~cm})$ drawn onto them.

Following measurement of the empty tank, its model was generated to which the model created after filling the tank with water was compared. Figure 4 demonstrates the tank fully filled with water secured during its filling for safety purposes and the

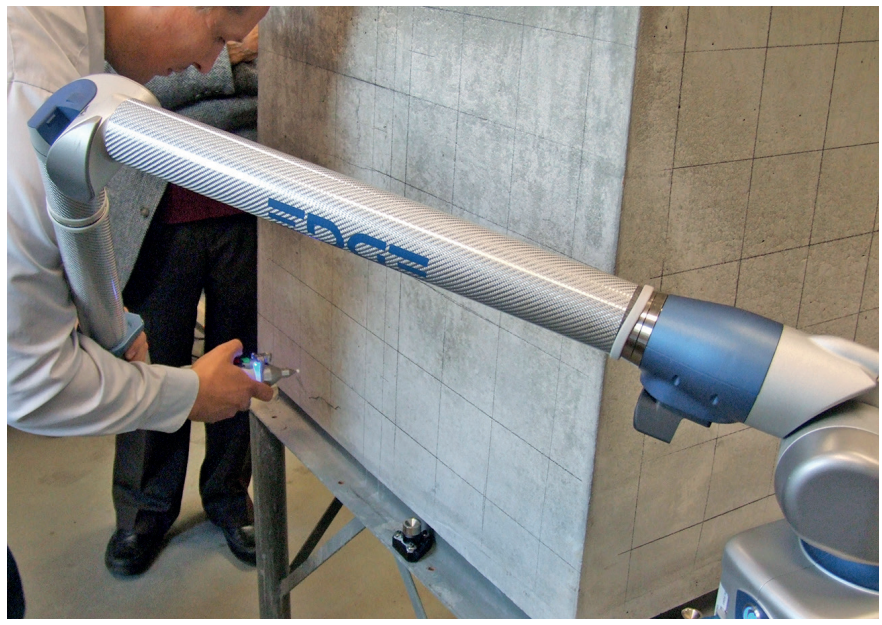

Fig. 3. Empty tank during measurements

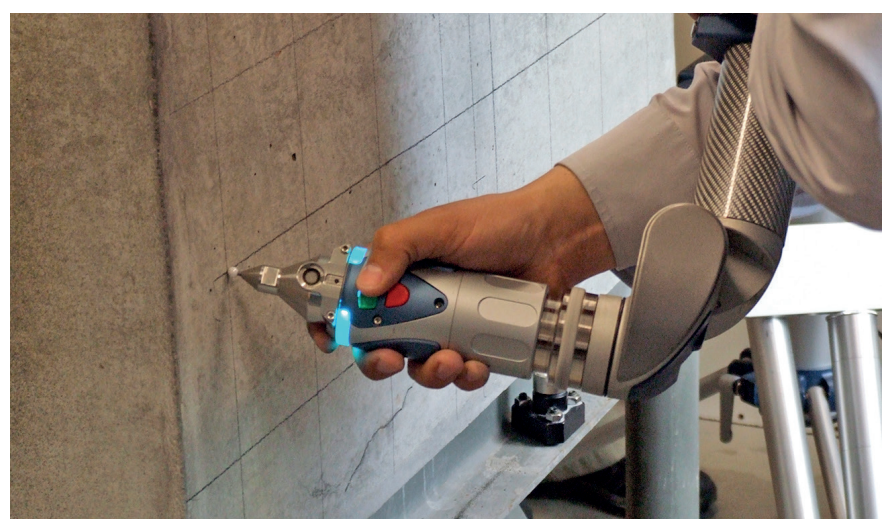

Fig. 4. Empty tank during measurements

moment of taking measurements. All protection equipment was removed during measurements. The location of the measurement arm stand remained unchanged and the working volume of the arm was sufficient to take measurements. Before measurements, the operator shifted the arm through reference points that had been placed on a steel frame supporting the tank. These are illustrated in Fig. 5 and Fig. 6.

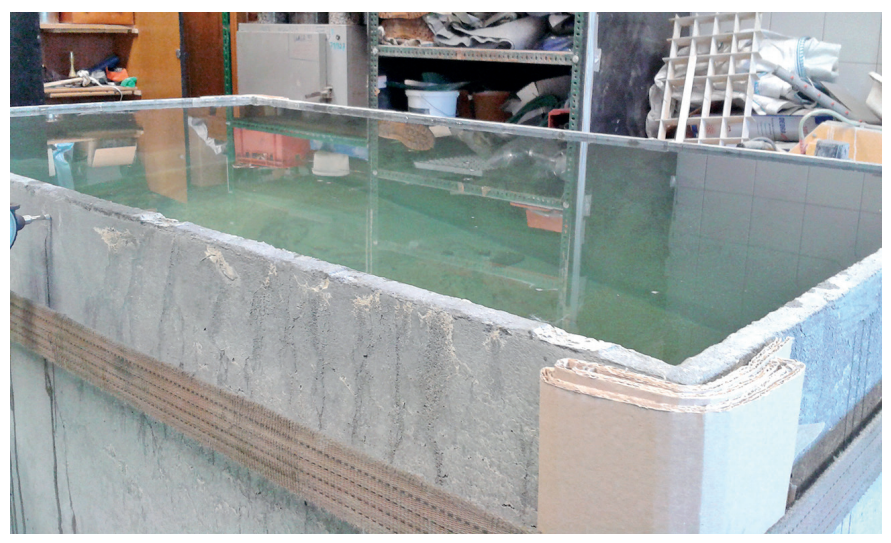

Fig. 5. Tank fully filled with water ready for deformation measurements

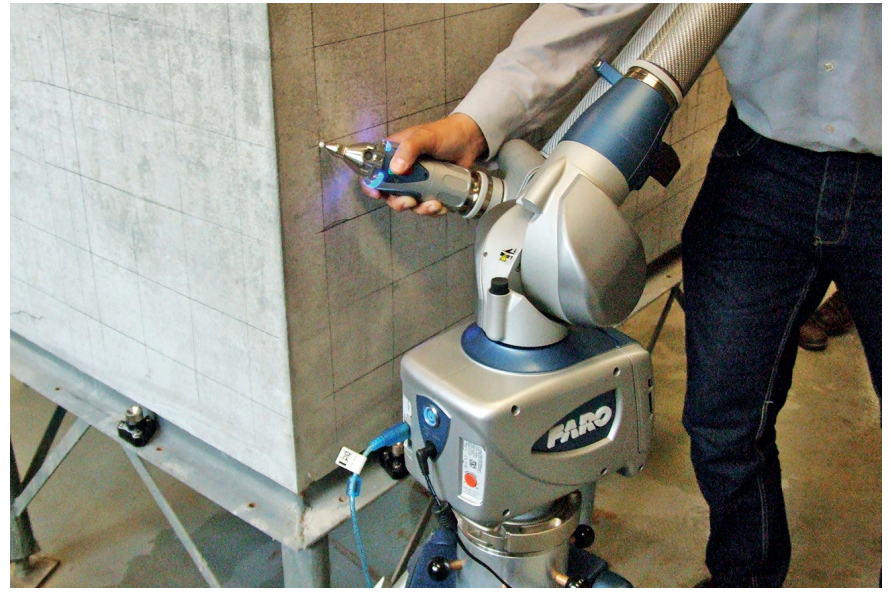

Fig. 6. Tank during measurements and visible reference points placed on a supporting steel frame 


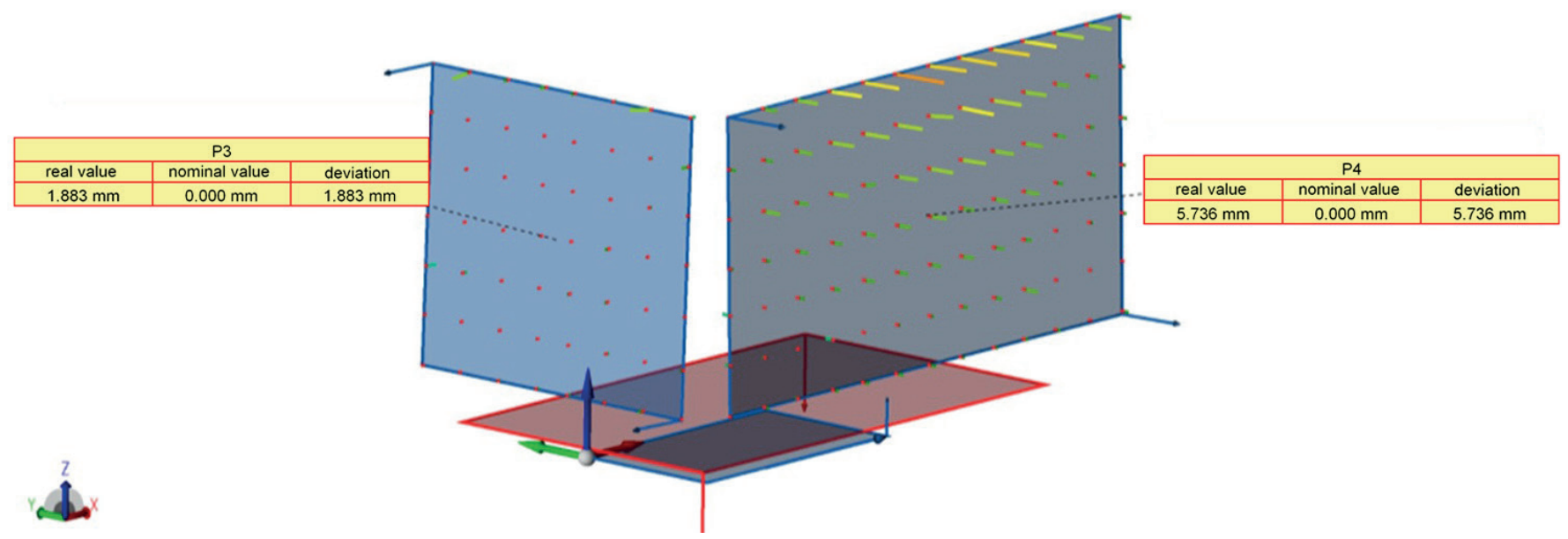

Fig. 7. Schematic model of the tank, generated by software

Figure 7 shows the visualisation of measurements by Cam2Measure [18], illustrating two walls of the tank included in measurements, the modelled bottom, and the location of measurements at intersections of the measuring mesh drawn onto the tank along with the deformations measured.

\section{Analysis of the results}

Conventional FDM calculations and calculations made with the use of engineering software enabled to obtain deformation values for all points of the applied mesh. Measurements with the use of a coordinate measurement arm were also taken for these points. Analysis of the results included several specified points in measured walls. Figure 8 shows points for which the results were compared.

Table 2 summarizes the values of deformations for points shown in Fig. 8. The summary includes the values of deformations obtained on the basis of traditional calculations, by means of using software as well as measurements taken with the use of a measuring arm.
Table 2.

Summary of deformation values for points shown in Fig. 7

\begin{tabular}{|c|c|c|c|}
\cline { 2 - 4 } \multicolumn{1}{c|}{} & \multicolumn{3}{c|}{ Deformation values } \\
\hline $\begin{array}{c}\text { Point } \\
\text { number }\end{array}$ & $\begin{array}{c}\text { Traditional } \\
\text { method FDM }\end{array}$ & $\begin{array}{c}\text { Autodesk Robot } \\
\text { Structural } \\
\text { Analysis } \\
\text { Professional }\end{array}$ & $\begin{array}{c}\text { Experimental } \\
\text { measurements } \\
\text { taken with } \\
\text { FaroArm }\end{array}$ \\
\hline $\mathbf{1}$ & $0.159 \mathrm{~mm}$ & $0.160 \mathrm{~mm}$ & $0.132 \mathrm{~mm}$ \\
\hline $\mathbf{2}$ & $0.179 \mathrm{~mm}$ & $0.180 \mathrm{~mm}$ & $0.144 \mathrm{~mm}$ \\
\hline $\mathbf{3}$ & $0.189 \mathrm{~mm}$ & $0.190 \mathrm{~mm}$ & $0.211 \mathrm{~mm}$ \\
\hline $\mathbf{4}$ & $0.097 \mathrm{~mm}$ & $0.100 \mathrm{~mm}$ & $0.093 \mathrm{~mm}$ \\
\hline $\mathbf{5}$ & $0.098 \mathrm{~mm}$ & $0.100 \mathrm{~mm}$ & $0.110 \mathrm{~mm}$ \\
\hline
\end{tabular}

The diagrams below illustrate the correlation between test results drawn for deformation values at all points of the mesh on the tank wall with $143 \mathrm{~cm}$ in length. Very high conformity of results between FDM and FEM solutions was obtained, with the coefficient of determination $\mathrm{R}^{2}=0.99$, as shown in Fig. 9. For FaroArm, the correlation between the FDM solution and
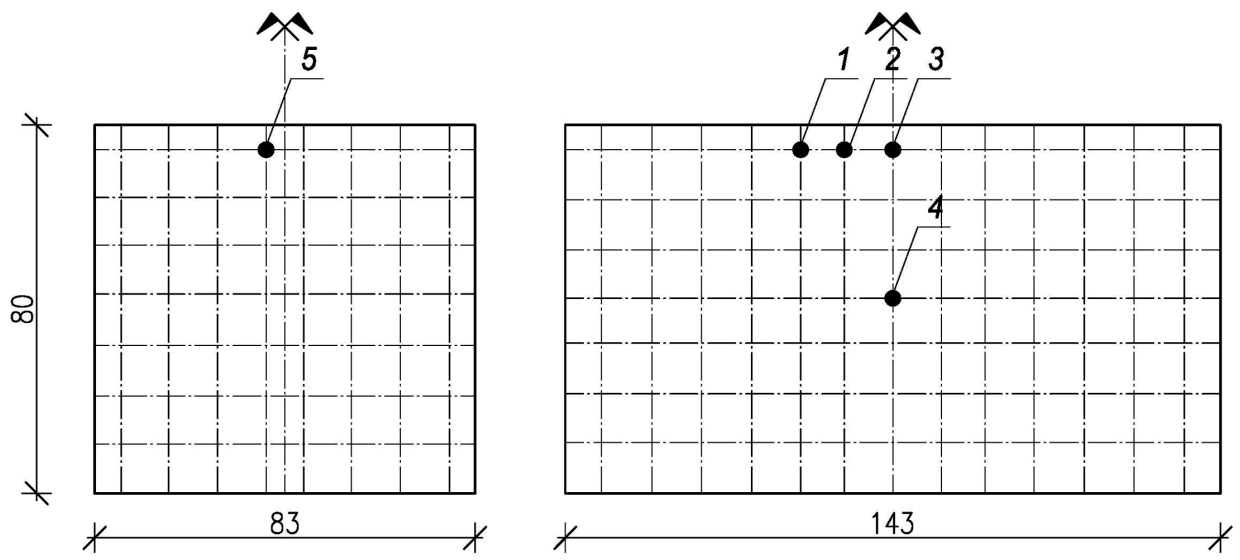

Fig. 8. Schematic drawing of walls with points for which deformation values were compared 

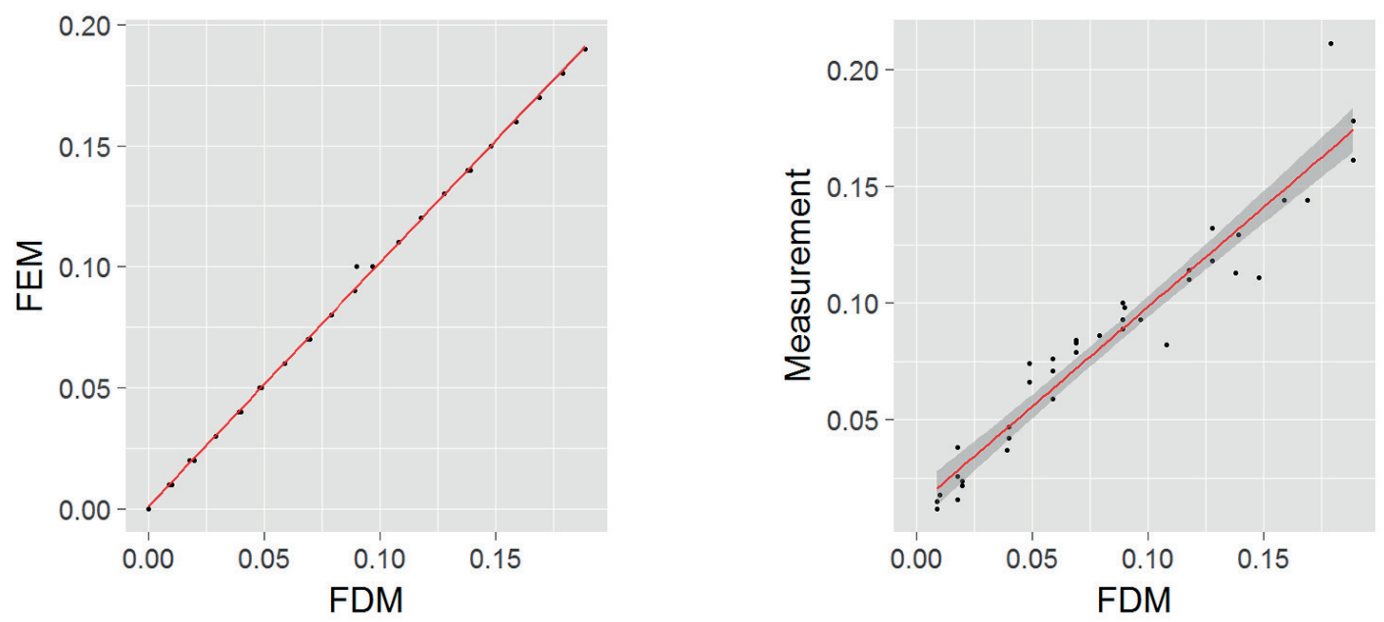

Fig. 9. Correlation between FDM and FEM (left) and correlation between FDM solution and FaroArm measurements (right)

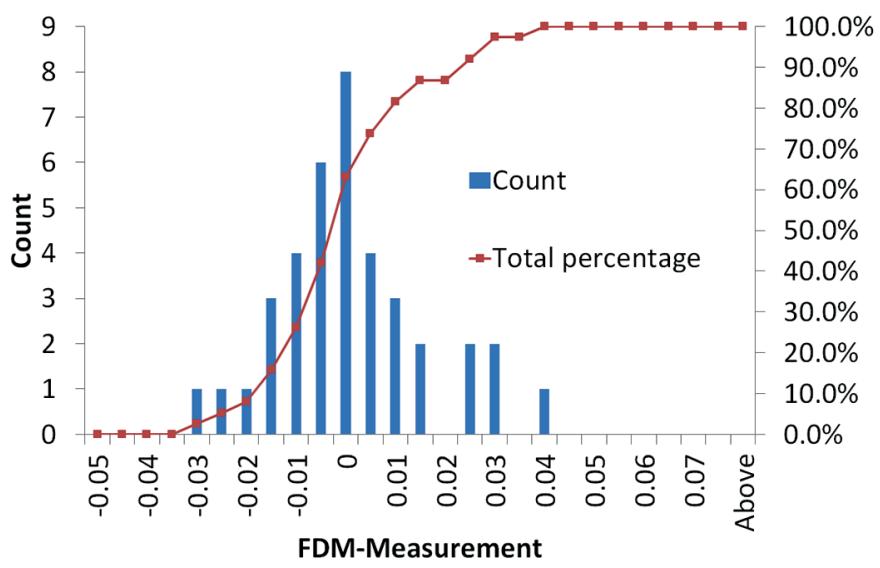

Fig. 10. Histogram of differences between FDM results and FaroARM measurement

laboratory measurements shown in Fig. 9 remained at the level of $\mathrm{R}^{2}=0.93$. The error distribution analysis performed on the basis of differences between the analytical solution and FaroArm measurement for all points is presented in the histogram shown in Fig. 10. 25 class intervals in the range of $-0.05-0.075 \mathrm{~mm}$, every $0.005 \mathrm{~mm}$, were applied. The height of bars presents the number of errors included within a given interval. Thus, the histogram in Fig. 9 indicates that for $71 \%$ of measurements the measuring error with respect to the results obtained by the finite difference method is to be found within the interval of between -0.015 and $0.015 \mathrm{~mm}$. The error is less than $10 \%$ of the designated maximum deformation. Meanwhile, 21\% of measurements are classified within the interval of between -0.005 and $0 \mathrm{~mm}$ (approx. 3\% of maximum deformation).

\section{Summary}

Validation of calculations made by means of the coordinate measurement arm provided an opportunity to confirm their cor- rectness. The coherence achieved stands as evidence for relevance of the calculation methods applied, i.e. the finite element method, which gave basis to Autodesk Robot Structural Analysis Professional calculations, as well as the finite difference method in terms of energy, used for traditional calculations. Measurements taken on a real object, i.e. a concrete tank made at the Concrete Laboratory of Institute of Civil Engineering and Geoengineering, Poznań University of Life Sciences, demonstrate that portable coordinate measurement arms with a rigid touch probe can also be applied for the verification of building structures.

Acknowledgements. The authors would like to thank $\mathrm{Mr}$ Michał Młyńczak from Faro Technologies for providing the FaroArm measuring device and enabling measurements.

\section{REFERENCES}

[1] A. Halicka and D. Franczak, Design of Reinforced Concrete Tanks. Volume 1. Tanks for Bulk Materials, Wydawnictwo Naukowe PWN, Warszawa, (2014), [in Polish].

[2] PN-EN 1992-1-1:2008 Eurocode 2: Design of concrete structures. Part 1-1: General rules and rules for buildings.

[3] W. Buczkowski, "Solution of beams of changeable rigidity with use of finite-difference method", Acta Scientiarum Polonorum. Architectura 8(3-4) (2009) [in Polish].

[4] FARO Edge and FARO Laser ScanArm Edge Manual. Faro (April 2016).

[5] Z. Kączkowski, Plates. Static Calculations, Arkady, Warszawa, 2000 [in Polish]

[6] J. Gołaś, Introduction to the Theory of Plates, Wydawnictwo Wyższej Szkoły Inżynierskiej, (1972), [in Polish].

[7] W. Buczkowski and H. Mikołajczak, "The application of finite difference method for static calculation of unusual, one-chamber rectangular tanks", in Design and implementation technology of tanks, 31-38, (1985), [in Polish].

[8] W. Buczkowski, "Reflections on static calculations for rectangular tanks", Inżynieria i Budownictwo 3, 153-154, (1997), [in Polish]. 
[9] W. Buczkowski and A. Szymczak-Graczyk, "The influence of different thickness and construction of walls on static works of monolithic rectangular tanks", Acta Scientiarum Polonorum. Architectura 7(3) (2008) [in Polish].

[10] W. Buczkowski, A. Szymczak-Graczyk, and Z. Walczak, "The analysis of static works of closed monolithic rectangular tanks". Durability and Repair of Building Structures, Dolnośląskie Wydawnictwo Edukacyjne, Wrocław, (2015).

[11] R. Paruch, "Computer-aided design with the use of Robot Structural Analysis in terms of BIM", Mechanik 7 (2015) [in Polish].

[12] A. Halicka and D. Franczak, "Design of reinforced concrete tanks. Tom 2. Tanks for liquids", Wydawnictwo Naukowe PWN, Warszawa, (2014), [in Polish].

[13] T. Błaszczyński, M. Babiak, and P. Wielentejczyk, "The use of numerical methods for the analysis of damage caused by fire in the biomass silo", Materiaty Budowlane 9 (2015), [in Polish].
[14] M. Sybis, A. Smoczkiewicz-Wojciechowska, and A. SzymczakGraczyk, "The analysis of complexity of the finite difference method (FDM) and the finite element method (FEM) exemplified by a beam element", Design, operation, diagnostics and repair of selected structures of general and hydro-technical construction, Institute of Civil and Geoengineering, Poznań University of Life Sciences, Poznań, (2015), [in Polish].

[15] E. Ratajczyk, "Coordinate measurement arms for industrial applications", Pomiary, Automatyka, Robotyka 3 (2012).

[16] E. Ratajczyk, "Measurement arms - scanning and special measurements, measurements in an extended range, software", Mechanik 1 (2009) [in Polish].

[17] E. Ratajczyk, M. Rak, and T. Kowaluk, "The influence of the method for collecting points on results with the use of a measurement arm", Metrology and Measurement Systems 3 (2012).

[18] Cam2 Measure 10. Manual v 10.7. Faro (February 2017). 